\title{
DUAS ESPÉCIES NOVAS DE ANTHIDIINAE DO BRASIL (HYMENOPTERA, MEGACHILIDAE) 1
}

\author{
Jesús S. Moure ${ }^{2}$ \\ Danúncia Urban ${ }^{2}$
}

\begin{abstract}
TWO NEW SPECIES OF ANTHIDIINAE FROM BRASIL (HYMENOPTERA, MEGACHILIDAE). Saranthidium marginatum, sp.n. from Brazil (Minas Gerais and Parana) and Argentina (Misiones) and Hypanthidium erythrogaster, sp.n. from Brazil (Bahia, Espirito Santo, Rio de Janeiro, Minas Gerais and Mato Grosso do Sul) are described.

KEY WORDS. Anthidiinae, Megachilidae, Taxonomy
\end{abstract}

Descreve-se duas espécies de Dianthidiini bastante comuns no Sudeste do Brasil: Saranthidium marginatum, sp.n. do Brasil (Minas Gerais e Paraná) e Argentina (Misiones), única espécie do gênero com o tegumento preto no sexto tergo da fêmea e Hypanthidium erythrogaster, sp.n. do Brasil (Bahia, Espírito Santo, Rio de Janeiro, Minas Gerais e Mato Grosso do Sul) facilmente identificada pelo colorido ferrugíneo-avermelhado do metasoma. Saranthidium foi proposto por MOURE \& HURD (1960) como sub-gênero de Hypanthidium Cockerell, 1904, porém GRISWOLD e MICHENER (1988) o reconheceram como gênero distinto.

\section{Saranthidium marginatum, sp.n.}

Diagnose. Fêmea com o sexto tergo inteiramente preto e pernas posteriores castanho-enegrecidas, com faixa amarela discal no primeiro e do terceiro ao quinto tergo. Macho de cabeça predominantemente amarela com tonalidade ferrugínea e área preta médio-dorsal incluindo parte da fronte e do vértice, e faixas nos tergos como na fêmea, pernas amarelo-ferrugíneas com áreas basais negras.

Holótipo macho. Tegumento da cabeça amarelo, mais pálido no clípeo e paroculares inferiores e com uma tonalidade ferrugínea na área supraclipeal, parte proximal da fronte, paroculares superiores e estreita faixa na metade posterior do vértice prolongada em estria pós-ocular até a base das mandíbulas, estas com orla enegrecida; grande área preta no restante da fronte e parte do vértice, alcançando os olhos ao nível dos ocelos laterais; labro e occipício pretos;

1) Contribuição número 807 do Deparatmanto de Zoologia, Universidade Federal do Paraná.

2) Departamento de Zoologia, Universidade Federal do Paraná, Caixa Postal 19020, 81531-970 Curitiba, Paraná, Brasil. 
antenas de um amarelo-acastanhado, mais pálido no escapo ventralmente e no lado dorsal de uma tonalidade mais escura a partir do quarto flagelômero. Mesosoma e metasoma pretos com as seguintes áreas mais claras: lobos pronotais com nódoa amarela junto ao espiráculo; tégulas ferrugíneas; mesoscuto com estrias laterais amarelas com leve mistura de ferrugíneo prolongadas na base, mais largas e um pouco projetadas para o disco, porém amplamente separadas uma da outra; escutelo e axilas com larga margem amarelo-ferrugínea; mesepisternos com grande mancha discal amarelo-acastanhada levemente separada de outra amarela mais ventral. Pernas amarelo-ferrugíneas, as anteriores enegrecidas na base do fêmur, nas medianas a coxa, trocânter e parte do fêmur enegrecidos e nas posteriores os três artículos basais pretos, com área amarelo-acastanhada junto às articulações, fêmures anteriores e medianos e basitarsos posteriores com estria amarela. Asas escuras. Segundo tergo castanho com duas nódoas laterais amarelas, demais tergos castanhos com faixa discal amarela larga, no sétimo orla e face ventral castanhas; esternos castanhos com amarelo no primeiro e segundo, nos demais o amarelo reduzido a estreita faixa.

Comprimento aproximado $7,08 \mathrm{~mm}$; comprimento da asa anterior $6,42 \mathrm{~mm}$, largura da cabeça $2,52 \mathrm{~mm}$; comprimento do olho $1,96 \mathrm{~mm}$; distância interorbital superior $1,40 \mathrm{~mm}$ e a inferior $1,16 \mathrm{~mm}$.

Alótipo fêmea. Tegumento preto com as seguintes áreas coloridas na cabeça: mandíbulas com área subapical e basal ferrugíneas, o tubérculo basal amarelo; clípeo com a margem preta em arco e duas grandes áreas basais pretas, o restante amarelo com algo de ferrugíneo para a base; área supraclipeal e proximidades da fronte com grande nódoa amarelo-ferrugínea com forma de $\mathrm{H}$ e outra alongada próxima à sutura epistomal; áreas paroculares amarelas passando para amarelo-ferrugíneas superiormente; metade posterior do vértice com faixa amarela ferrugínea que se prolonga em larga estria pós-ocular; antenas desta cor ventralmente e mais castanhas por cima a partir do terceiro flagelômero. Mesosoma como no macho, porém com uma única nódoa amareloferrugínea nos mesepisternos. Pernas mais escuras que as do macho, as anteriores com trocânter e base do fêmur enegrecidos, nas medianas o enegrecido chegando até o meio do fêmur e as posteriores castanho-enegrecidas com ferrugíneo na coxa. Tergos enegrecidos, no segundo com nódoas laterais amarelas, os demais com faixa amarela discal, mais larga e completa no primeiro e pouco interrompida no meio do terceiro ao quinto; esternos enegrecidos com grande área amarela ferrugínea no primeiro e segundo. Escopa ventral branca. Comprimento aproximado $8,50 \mathrm{~mm}$; comprimento da asa anterior $6,25 \mathrm{~mm}$; largura da cabeça $2,68 \mathrm{~mm}$; comprimento do olho $2,0 \mathrm{~mm}$; distância interorbital superior $1,56 \mathrm{~mm}$ e a inferior $1,28 \mathrm{~mm}$.

Variações. Uma fêmea do Rio Paraná (Paraná) e outra de Sta. Rita de Cássia (Minas Gerais) sem nódoa amarelada nos mesepisternos, as nódoas pretas basais do clípeo quase fundidas ou pequenas e distanciadas. Nos machos apenas uma nódoa discal nos mesepisternos, podendo estar reduzida ou mais escura; redução das faixas dos tergos, ou duas pequenas nódoas amarelas além 
das laterais no segundo tergo.

Holótipo e um parátipo macho com as etiquetas: /Passos-MG Brasil 25-31-V-63 Claudionor Elias [leg.]//Holótipo/ /Saranthidium marginatum Moure \& Urban det. 1993/. Alótipo da mesma localidade coletado entre 28-XI e 7-XII-62 por C. Elias. Parátipos: Brasil, Minas Gerais, Passos, C. \& C.T. Elias leg. X-1963 um macho; C. Elias leg., 10-15 VI 1963 uma fêmea; Sta. Rita de Cassia, C. Elias leg., 23-30-IX-1969 uma fêmea. Paraná, Fóz do Iguassú, Sakagami \& Laroca leg., I-62 uma fêmea; Rio Paraná, C. Goffergé leg., II-48, 2 machos e uma fêmea. Argentina, Misiones, Iguazú, Hayward, Willink \& Golbach leg., 30-I a 13-III-45 um macho e uma fêmea. Depositados na Coleção de Entomologia Pe. J.S. Moure, Departamento de Zoologia da Universidade Federal do Paraná; um macho e uma fêmea parátipos no Instituto Miguel Lillo, Tucumán, Argentina.

\section{Hypanthidium erythrogaster, sp.n.}

Diagnose. Caracterizado facilmente pelos tergos e esternos ferrugíneoavermelhados, tanto no macho como na fêmea.

Holótipo macho. Tegumento da cabeça e mesosoma preto com as seguintes áreas de cores mais claras: amarelo em quase toda a face externa das mandíbulas, com o preto reduzido aos bordos e os dentes; grande parte do clípeo porém deixando duas áreas basais pretas do meio até a base; larga estria amarela nas paroculares, contínua com o amarelo do clípeo porém muito estreitada em direção ao vértice e terminando na altura do ocelo médio; duas estrias interalveolares amarelas arqueadas em direção aos alvéolos; faixa delgada amarela na metade posterior do vértice prolongada atrás dos olhos até a base das mandíbulas; escapo amarelo na face ventral. Lobos pronotais com pequena nódoa acastanhada; tégulas quase pretas com orla castanha; mesoscuto com finas estrias amarelas laterais prolongadas na base e amplamente separadas; axilas e escutelo com fina margem amarela; mesepisternos com área ventral e nódoa discal amarelas; metepisternos amarelos ventralmente. Pernas com grandes áreas pretas e ferrugíneas e nódoas amarelas, as anteriores com ferrugíneo na coxa, face anterior do fêmur e quase toda a tíbia, mais amarelo no lado externo dos basitarsos, demais tarsômeros amarelo-ferrugíneos; as medianas amarelo-ferrugíneas na coxa, com estria amarela na face posterior do fêmur, ápice do fêmur e quase toda a tíbia amarelo-ferrugínea, tarsômeros enegrecidos; as posteriores com grande nódoa amarela na coxa e ápice do fêmur e da tíbia e lado externo dos basitarsos, face anterior e lateral da tíbia amarelo-ferrugínea com invasão de preto no disco, os demais tarsômeros enegrecidos. Asas escuras. Metasoma ferrugíneo avermelhado, irregularmente manchado no disco dos tergos, do primeiro ao quarto tergo com pequena nódoa amarela lateral orlada em parte de preto, quinto e sexto com pequenas faixas laterais enegrecidas, no sexto com pequena nódoa amarela subapical a cada lado e larga área discal amarelada, sétimo orlado de preto; segundo esterno com nódoas laterais amarelas. 
Comprimento aproximado $8,5 \mathrm{~mm}$; comprimento da asa anterior $8,17 \mathrm{~mm}$; largura da cabeça $3,17 \mathrm{~mm}$; comprimento do olho $2,16 \mathrm{~mm}$; distância interorbital superior $1,80 \mathrm{~mm}$ e a inferior $1,40 \mathrm{~mm}$.

Alótipo fêmea. Cabeça e mesosoma pretos com áreas amarelo-claras: nódoa disco-basal e outra menor basal nas mandíbulas; nódoa subapical nos lados do clípeo, estria parocular muito delgada na metade superior; faixa estreita na metade posterior do vértice prolongada atrás dos olhos até a meia distância das mandíbulas; face ventral do escapo amarelenta; tégulas pretas com fina orla castanha; mesoscuto e axilas como no macho; escutelo com faixa apical amarela muito estreita e interrompida no meio; mesepisternos com nódoa discal muito pequena. Pernas enegrecidas com estria amarela na face posterior dos fêmures anteriores e medianos e nos posteriores uma nódoa subapical, face anterior das tíbias anteriores com estria ferrugínea e nas medianas com pequena nódoa subapical amarelada. Metasoma ferrugíneo avermelhado com área amarelada nos flancos do primeiro tergo e áreas escuras irregulares no segundo e terceiro, preto no ápice do tergo distal; esternos como nos tergos e enegrecidos no meio, o distal enegrecido.

Comprimento aproximado $8,17 \mathrm{~mm}$; comprimento da asa anterior $7,50 \mathrm{~mm}$; largura da cabeça $3,25 \mathrm{~mm}$; comprimento do olho $2,32 \mathrm{~mm}$; distância interorbital superior $1,80 \mathrm{~mm}$ e a inferior $1,44 \mathrm{~mm}$.

Variações. Nos machos foi observada principalmente uma extensão do amarelo no clípeo, separando completamente as nódoas negras basais, reduzindo-as a menos de um terço do comprimento do clípeo ou ainda as nódoas quase inteiramente fundidas no disco; lobos pronotais pretos ou com nódoa amarela; tergos com áreas discais mais amareladas em forma de faixas; flancos do primeiro ao sétimo tergo com nódoa amarela orlada de preto. Nas fêmeas foi constatada a ocorrência de clípeo inteiramente preto e clípeo com nódoas laterais amarelas em espécimens da mesma localidade; estria parocular amarela muito estreita ou interrompida; estrias laterais do mesoscuto separadas da parte basal; entre exemplares coletados em Conceição da Barra, alguns com lobos pronotais, mesepisternos e escutelo pretos, ao lado de exemplares com nódoa amarela nas referidas áreas; nódoa amarela dos mesepisternos reduzida ou até maior que o diâmetro do flagelo; quanto ao metasoma, uma fêmea de Vitória da Conquista com ferrugíneo avermelhado só nos dois segmentos basais, nos restantes castanho-enegrecido com uma leve tonalidade avermelhada, e exemplares com faixas laterais amareladas nos flancos do primeiro ao quinto tergo.

Distribuição geográfica. BRASIL: Bahia, Espírito Santo, Rio de Janeiro, Minas Gerais e Mato Grosso do Sul.

Holótipo macho com as etiquetas: /Sta. Tereza-V [ista] Alegre ES [Espírito Santo] BR 13-17 III 67 C. \& C.T. Elias leg./ Dpto. Zool. UF-Paraná/ Holótipo/ Hypanthidium erythrogaster Moure \& Urban det. 1993/. Alótipo fêmea com os mesmos dados do holótipo. 554 parátipos, sendo 204 fêmeas e 350 machos das seguintes localidades: Bahia, Ilhéus, S. Laroca leg., 16-IV-65, dois machos e uma fêmea; Vitória da Conquista, F.M. Oliveira leg., 5 a 15-V-61, 42 
machos e 22 fêmeas; Maracás, F.M. Oliveira leg., VI-61, 12 machos e seis fêmeas; Jequié, C. e C.T. Elias leg., 15-XI-64, duas fêmeas; Prado, C. Elias leg., 5-III-71 um macho. Espírito Santo, C. e C.T. Elias leg., Baixo Guandú, 17-IX-66 a 7-VI-71, 41 machos e 28 fêmeas; Cariacica, 10-IV a 8-V-67, 11 machos e oito fêmeas; Colatina, 15-IV-66 a 4-VII-69, 37 machos e 26 fêmeas; Conceição da Barra, 18-IV a 3-X-68, 44 machos e 17 fêmeas; Domingos Martins, 16 a 28-II-66, nove machos e duas fêmeas; Fundão, 20-V-64 a 20-I-66, quatro machos; Itaguassu, 15-VI-67 a 25-IV-70, cinco machos e sete fêmeas; Itapina, 11-XII-67 a 21-XI-70, 13 machos e seis fêmeas; Jacaraipe, 11 a 18-II-67, 15 machos e seis fêmeas; Santa Teresa, 23-I-64 a 21-XII-71, 48 machos e 30 fêmeas; Sta. Leopoldina, 4-III-64 a 19-IV-67, oito machos e duas fêmeas; Sto. Antonio, 22-IV-66 uma fêmea; Sta. Maria, 21-I-67, quatro machos e uma fêmea; S. Domingos, 27-III-66, 21 machos e 14 fêmeas; S. Roque, 5-V-66 a 29-IV-67, seis machos e nove fêmeas; Serra - N. Almeida, 10 a 14-II-64, dois machos e uma fêmea; S.J. Petrópolis, 10 a 14-II-64, dois machos e uma fêmea, Linhares leg.; I-62 a 31-VII-72, dois machos e uma fêmea; F.M. Oliveira leg., 27-XI-67, oito machos e três fêmeas; P.A. Teles leg., V-53, uma fêmea. Rio de Janeiro, Paineiras, S. Lopes leg., 7-I-30, um macho e uma fêmea; Retiro Pedro do Rio, C.A.C. Seabra leg., III-54 a 25-I-57, um macho e quatro fêmeas. Minas Gerais, Juiz de Fora, A.G.A. Silva leg., 5-III-57, um macho; Belo Horizonte, F.M. Oliveira leg., VIII-61, três machos; Governador Valadares, K. Lenko leg., I- 58 uma fêmea: Viçosa, G. Melo leg., 29-III-85 dois machos; Perez e Maluf leg., 30-X-91 a 5-II-92, dois machos e uma fêmea; Sta. Bárbara, A.F. Kumagai leg., 13-14-IV-91, um macho. Mato Grosso do Sul, Dourados, J. Lorenzoni leg., I-76, dois machos e uma fêmea. Depositados na Coleção de Entomologia Pe. J.S. Moure, Departamento de Zoologia da Universidade Federal do Paraná.

O nome da espécie refere-se ao colorido avermelhado do metasoma.

\section{REFERÊNCIAS BIBLIOGRÁFICAS}

GRISWOLD, T.L. \& C.D. MICHENER 1988. Taxonomic observations on Anthidiini of the Western Hemisphere (Hymenoptera, Megachilidae). Journ. Kansas Ent. Soc. 61 (1): 22-45.

MOURE, J.S. \& P.D. HURD JR. 1960. On the systematic position of three Anthidiine bees described by Adolfo Ducke. Bol. Mus. Paraense Emilio Goeldi Zool. 28: 1-13.

Recebido em 30.X. 1993; aceito em 21.Il.1994. 